\title{
Ultrastructural study of the liver in hepatic porphyria
}

\author{
G. JEAN, G. LAMBERTENGHI, AND T. RANZI \\ From the Istituto di Patologia Speciale Medicà $\left(I^{\circ}\right)$, Università di Milano
}

SYNOPSIS In intermittent acute porphyria there are no specific alterations in the ultrastructure of the liver. In contrast, the constant characteristic of porphyria cutanea tarda is siderosis of the hepatocytes and Kupffer cells. Therefore, between the two types of hepatic porphyria there are no similar ultrastructural lesions. It is still doubtful whether the presence of hepatosiderosis in porphyria cutanea tarda is connected with the hepatopathy or is secondary to an alteration in the porphyrinic metabolism. The role played by lysosomes is discussed.

According to Watson (1960) and Eales (1963), hepatic porphyria can be classified into three different types (Tschudy, 1965): acute intermittent porphyria (manifest or latent); porphyria variegata (cutaneous with few or no acute manifestations or acute intermittent without cutaneous symptoms or various combinations or latent); symptomatic porphyria, porphyria cutanea tarda symptomatica (idiosyncratic, associated with alcoholism, liver disease, or induced by drugs).

The ultrastructural changes in the liver in hepatic porphyria are quite unknown: in fact, only Perloth, Tschudy, Marver, Berard, Ziegel, Rechcigl, and Collins (1966) have examined the ultrastructure of liver in a case of intermittent acute porphyria; in 'porphyria cutanea tarda' no submicroscopic study of liver has been published although there are many light microscopy studies of the histological liver picture (Schmid, Schwartz, and Watson, 1954; Bolgert and Canivet, 1956; Tuffanelli, 1960; Berlin and Brante, 1962; Eales, 1963; Dowdle and Saunders, 1963; Uys and Eales, 1963; Alessandrini, Nazzaro, and Topi, 1964; Prato, Chiandussi, Massaro, Mazza, and Zina, 1964; Thaler, 1964; Schnack and Wewalka, 1964).

There are two ultrastructural studies on rats treated with allylisopropylacetamide, a drug which induces certain metabolic alterations like those observed in human acute intermittent porphyria, namely, increased production of aminolevulinic acid and porphobilogen (Biempica, Kosower, Roheim, London, and Novikoff, 1966; Moses, Suskind, Tschudy, and Marver, 1966).

\section{MATERIAL AND METHODS}

The present study is based upon the examination of one liver biopsy from a patient with acute intermittent

${ }^{1}$ Via Pace, 15 Milano, Italy

Received for publication 16 November 1967. porphyria and of seven liver biopsies from patients with porphyria cutanea tarda.

Tissues for light microscopy were fixed in formalin. After embedding in paraffin sections were stained with haematoxylin and eosin, by the periodic acid-Schiff method, by Perls' method for iron and by Long-ZielNielsen's method for lipofuscins.

Small fragments of tissue for electron microscopy were fixed in Palade-buffered osmium tetroxide at room temperature. The tissues were washed very briefly (about one minute) in distilled water and subsequently dehydrated in a graded series of acetone solutions. The dehydration was as short as possible to reduce shrinkage and extraction of tissue components, for example, glycogen granules) to a minimum. After conventional embedding in Vestopal W, sections were cut on an L.K.B. ultramicrotome with glass knives. Ultrathin sections were 'stained' with uranile acetate and $\mathrm{Pb}$-citrate and examined in a Hitachi $\mathrm{H} 11$ A electron microscope, using $75 \mathrm{Kv}$ acceleration potential.

\section{ACUTE INTERMITTENT PORPHYRIA}

In the case we examined, light microscopy did not show particular changes in the liver, whereas electron microscopy made clear numerous ultrastructural alterations. In most of the hepatocytes we observed giant misshapen mitochondria, containing filamentous material, and their matrices of decreased density (Fig. 1). In contrast, only a few hepatocytes exhibited vacuolar degeneration with ergastoplasmic degranulation. Steatosis was often present. Lipofuscin inclusions (Fig. 2) were very numerous. A constant characteristic was the enlargement of the perisinusoidal recesses; sometimes they were in direct communication with the intercellular spaces which also were dilated (Fig. 3). The space of Disse was enlarged and contained some collagen fibrils and an evident basement membrane; the microvilli of the hepatocyte vascular pole were reduced. Endothelial and Kupffer cells were hypertrophic. Sometimes 
bile canaliculi were widened and presented anomalous villi. Moreover, hepatocytes arranged themselves in tubules (Fig. 4) which closely resembled the bile canaliculi ('biliary hepatocytes') of Phillips and Steiner (1966).

\section{PORPHYRIA CUTANEA TARDA}

LIGHT MICROSCOPY Essentially the changes observed could be classified as liver cell damage accompanied by fibrosis or by cirrhosis. The frequency of these changes is noted in Table I. The mildest form of liver cell damage detected was fatty change, and siderosis constituted the most constant single abnormality. All of the seven livers examined histochemically for iron showed Perls-positive granules both in hepatocytes and in Kupffer cells.

\section{TABLE I}

LIVER CHANGES IN PATIENTS WITH PORPHYRIA CUTANEA TARDA SEEN ON LIGHT MICROSCOPY

\begin{tabular}{llccc}
$\begin{array}{l}\text { Case } \\
\text { No. }\end{array}$ & Histological Diagnosis & Steatosis & $\begin{array}{c}\text { Degree of } \\
\text { Siderosis }\end{array}$ & Lipofuscin \\
\hline 1 & Liver Fibrosis & + & C & + \\
2 & Liver Fibrosis & + & C & + \\
3 & Liver Cirrhosis & + & C & - \\
4 & Liver Fibrosis & + & C & + \\
5 & Liver Cirrhosis & + & C & - \\
6 & Liver Fibrosis & + & C & + \\
7 & Liver Cirrhosis & + & C & -
\end{tabular}

Liver siderosis can be graded $\mathrm{C}$ according to the classification of Uys and Eales (1963) ${ }^{1}$. In four cases, numerous lipofuscin granules were detected in hepatocytes with Long-Ziel-Nielsen's reaction.

ELECTRON MICROSCOPY Several lesions of hepatocytes of sinusoids and of bile canaliculi were observed. These ultrastructural changes are those found in various liver diseases finally presenting as cirrhosis: vacuolar degeneration of the ergastoplasm, steatosis, mitochondrial swelling, widening of intercellular spaces and of perisinusoidal recesses, increase of collagen fibrils, capillarization of the sinusoids, a greater number of bile canaliculi (Fig. 5).

Only in one case did we observe the presence of giant mitochondria with fibrillar inclusions like those noted in acute intermittent porphyria.

In two cases we found an increase of 'fat-storingcells' (Bronfenmajer, Schaffner, and Popper, 1966) and a greater number of fat droplets.

In all the cases, but in three particularly, we noticed obvious hyperplasia and hypertrophy of endothelial and Kupffer cells with marked phagocytic activity.

${ }^{1}$ Grade $\mathbf{C}$ siderosis is when haemosiderin granules are found in Kupffer cells and liver cells and in the portal tracts either lying free or in macrophages.
Finally, it must be underlined that in all cases, 'primary' lysosomes (Weissmann, 1965) were absent.

Iron pigment inclusions were constantly recognized both in hepatocytes and in Kupffer cells (Fig. 6). They seemed to be formed by characteristic ferritin molecules of $55 \mathrm{~A}^{\circ}$ diameter and by smaller granules $30 \mathrm{~A}^{\circ}$ diameter which are called 'ferrous micelles' (Figs. 7 and 8) by Richter (1957 and 1960) and by Kent (1965). Ferritin particles are most heavily concentrated along the periphery of theinclusions. Within the iron aggregates there was electron-dense material with ferrous micelles, whereas, siderosomes containing scarce iron (Fig. 7) consisted almost entirely of ferritin particles. Sometimes the iron pigment appeared to be surrounded by a membrane; in others, it was free in the cytoplasm in direct contact with other cytoplasmic structures.

\section{DISCUSSION}

ACUTE INTERMITTENT PORPHYRIA In acute intermittent porphyria, the presence of giant mitochondria containing filamentous material has already $\infty$ been reported by Perloth et al (1966). This type of mitochondrial modification is noted not only in various pathological conditions but also in histologically unchanged livers (David, 1964; Wills, 1965; Stein, Richter, and Brynjolfsson, 1966) so that it is impossible to assign to it a real pathogenetic value, although the mitochondria are involved in porphyrinic metabolism (Beretta-Anguissola, 1961; Tschudy, 1965).

An increased number of lipofuscin aggregates are found in most conditions (aging, hepatocyte lysis, $\frac{7}{0}$ etc). Lipofuscin is constituted by materials no longer digestible by lysosome enzymes ('residual bodies') (De Duve, 1964; Weissmann, 1965), so the reason for its storage in our patient is not clear as yet; we can only underline that Campbell (1963) also found numerous lipofuscin granules by light microscope in patients in South Africa affected by genetic porphyria.

Other ultrastructural changes, including vacuolization of endoplasmic reticulum, steatosis, widening of perisinusoidal recesses and the presence of the socalled biliary hepatocytes, are certainly occasionally $\mathrm{W}$ found and are of no aetiological value. We did not $\underset{\sigma}{\sigma}$ particularly notice any of the ultrastructural alterations (nucleolar hypertrophy, decreased ribosomes, presence of numerous coated vesicles) found in $\stackrel{\infty}{?}$ experimental porphyria induced in rats with allylisopropylacetamide (Biempica et al, 1966; Moses et al, 1966).

PORPHYRIA CUTANEA TARDA The crystalloid structures in giant mitochondria observed in acute 


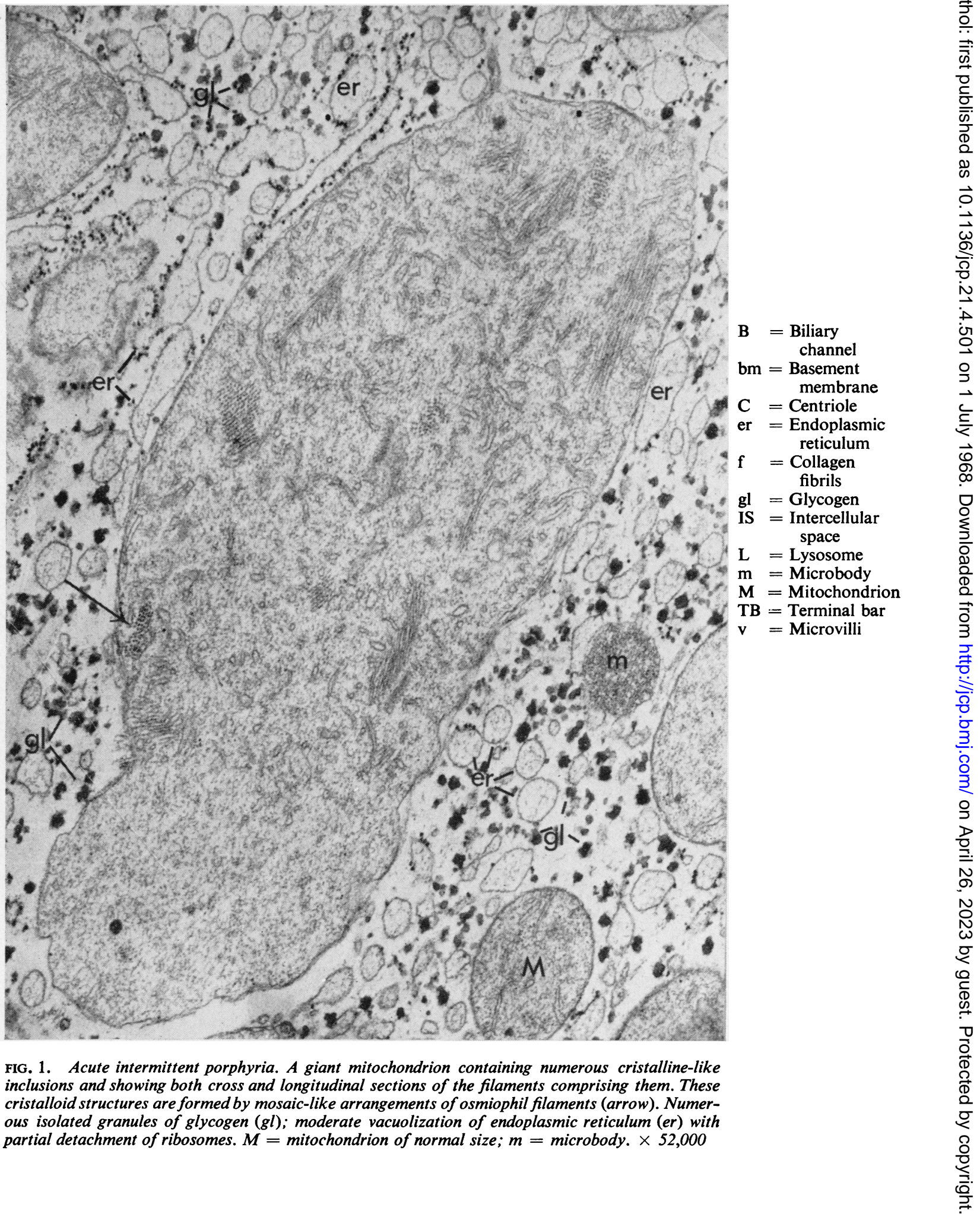



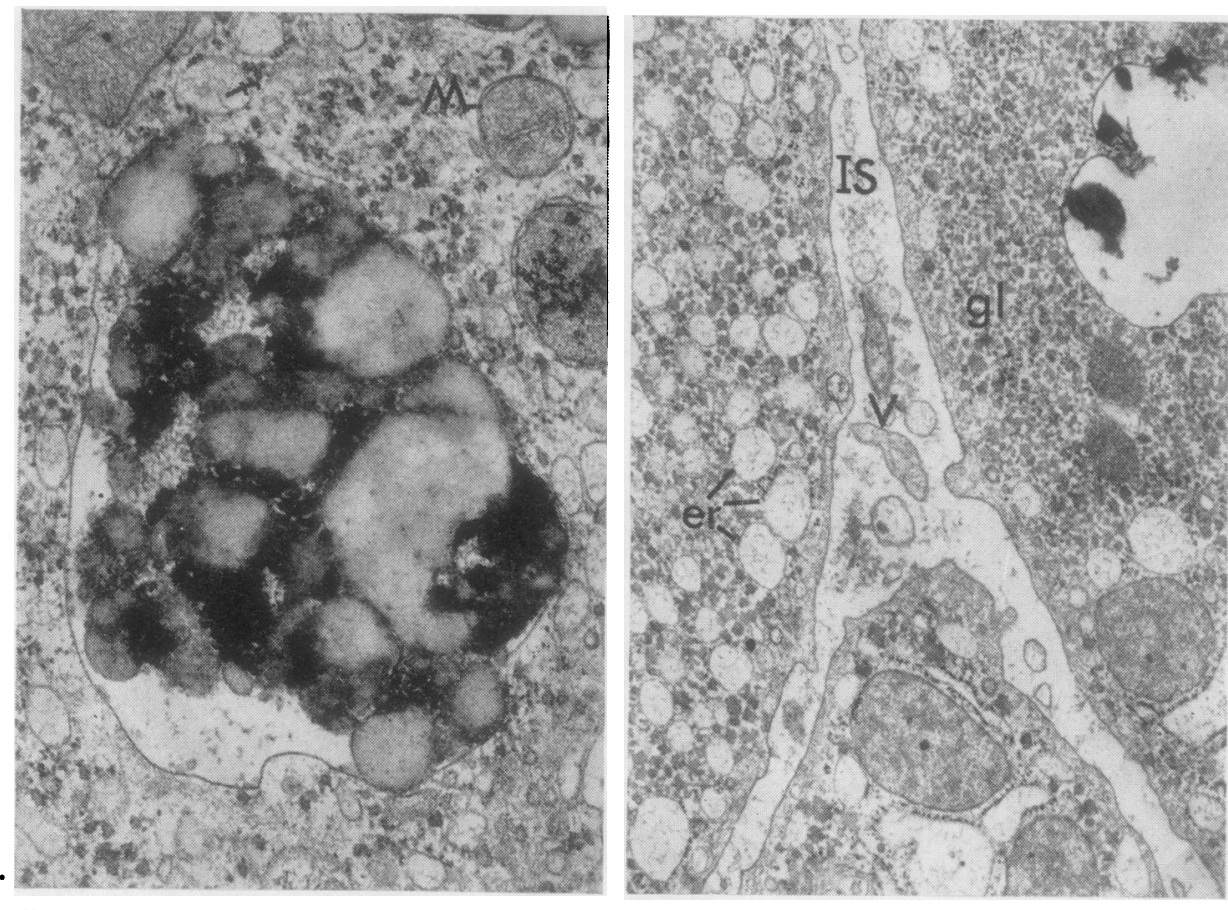

FIG. 2.

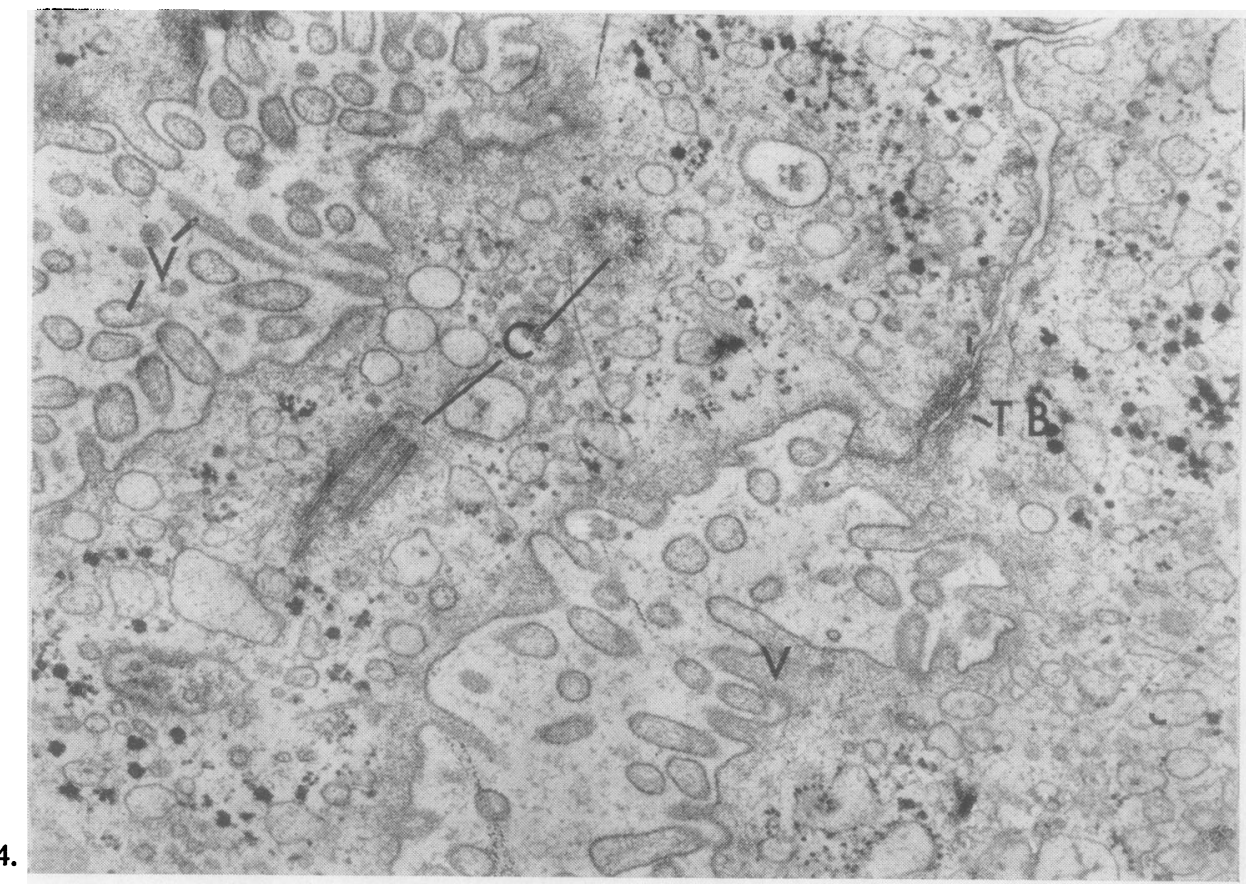

FIG. 3.

FIG. 4.

FIG. 2. Acute intermittent porphyria. Lipofuscin pigment enclosed in a vacuole; it consists of several bodies of moderate electron opacity separated from one another by opaque masses of granular appearance. $\times 35,000$

FIG. 3. Acute intermittent porphyria. Widening of the intercellular spaces (IS) among three hepatocytes; presence of rare microvilli (v) on contiguous lateral surfaces of the hepatocytes. Vacuolization of endoplasmic reticulum (er) of the left hand hepatocyte. Marked variation of glycogen ( $\mathrm{gl}$ ) granules distribution among the hepatocytes. $\times 28,000$

FIG. 4. Acute intermittent porphyria. Two large tubular lumina with well developed microvilli (v) and provided with terminal bars $(T B)$. The lumina are larger than those of the normal bile canaliculi. $C=$ Centrioles. $\times 31,000$ 


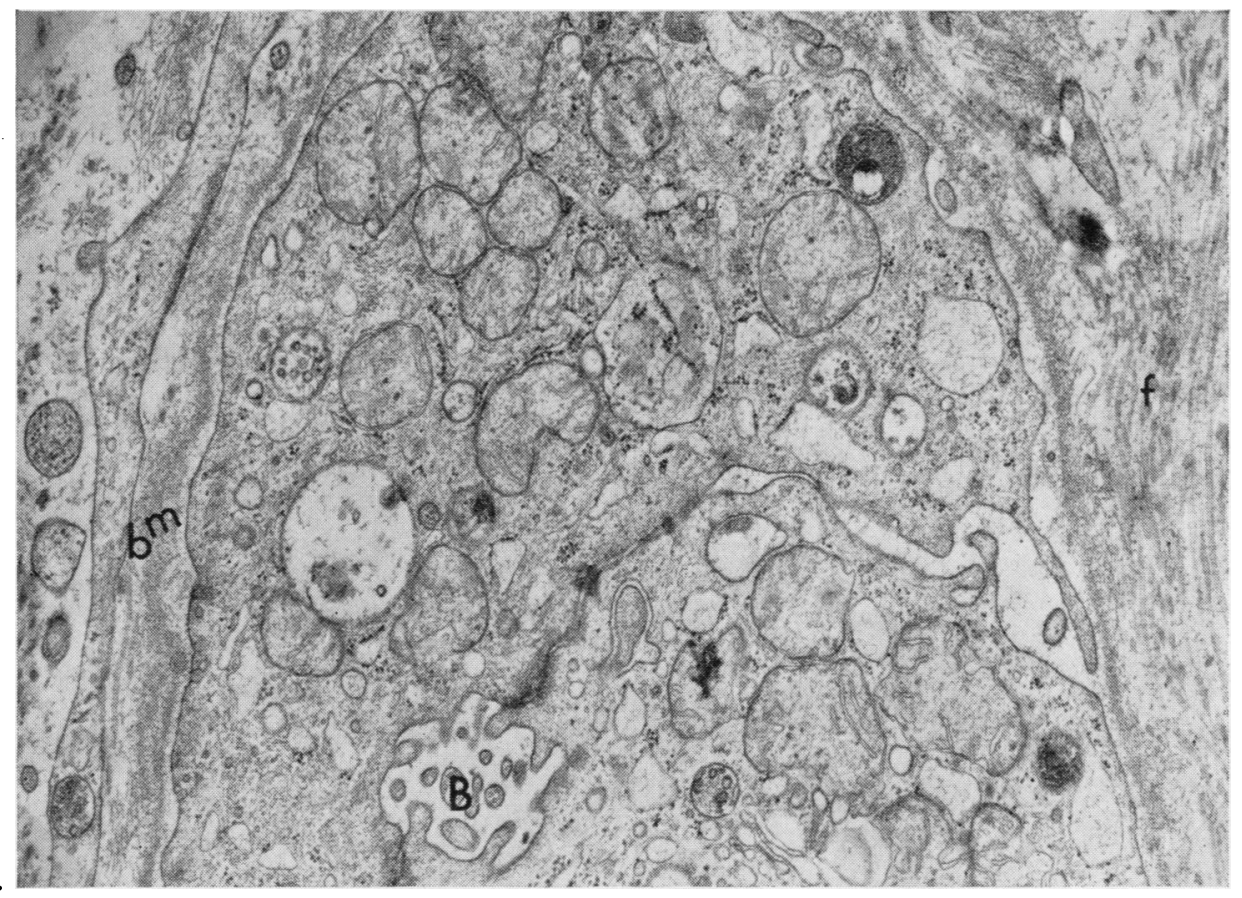

FIG. 5 .

FIG. 5. Porphyria cutanea tarda. A part of a biliary channel (B) surrounded by a basement membrane (bm) and connective tissue rich in collagen fibrils $(f)$. The lumen is lined exclusively by ductular cells. $\times 24,000$

FIG. 6. Porphyria cutanea tarda. A portion of a macrophage with lysosomes $(L)$ containing haemosiderin aggregates. $\times 20,000$

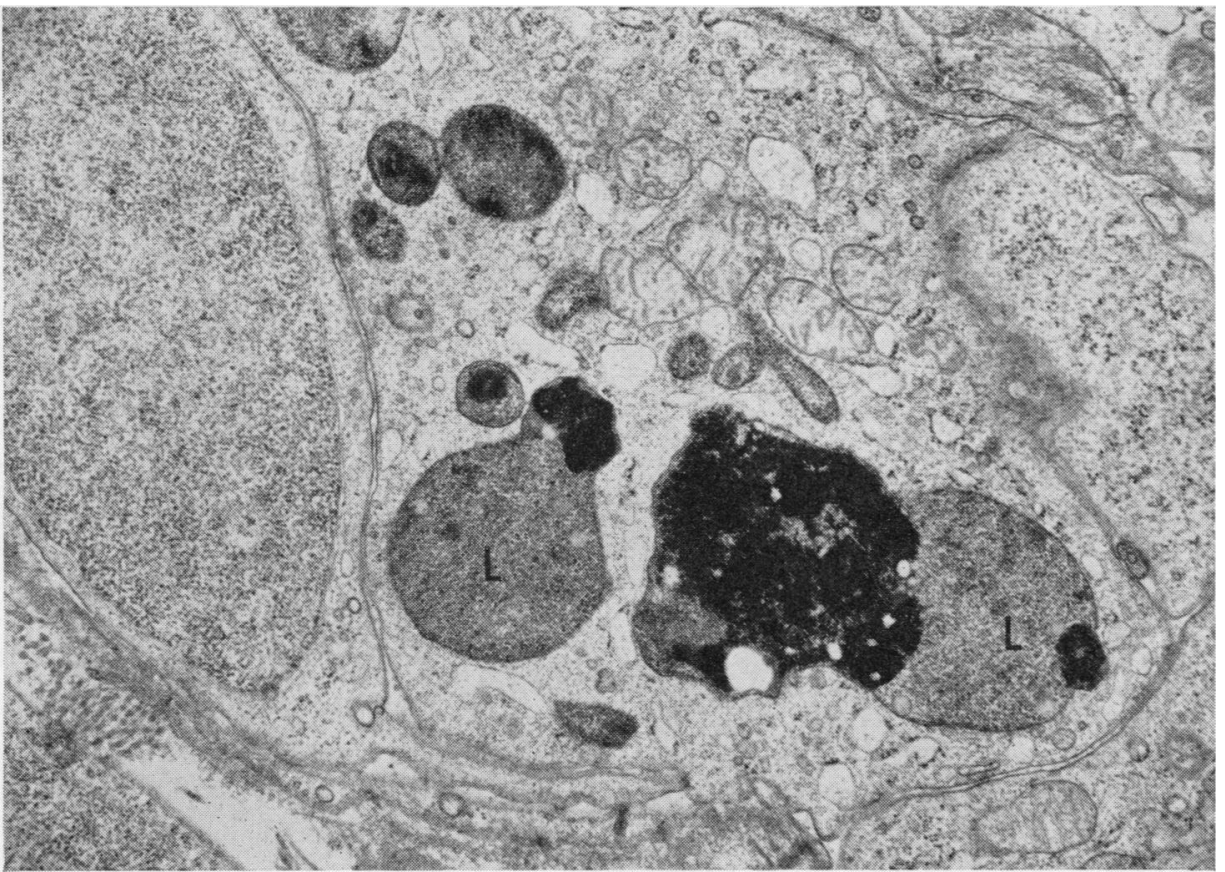

FIG. 6. 
FIG. 8 .

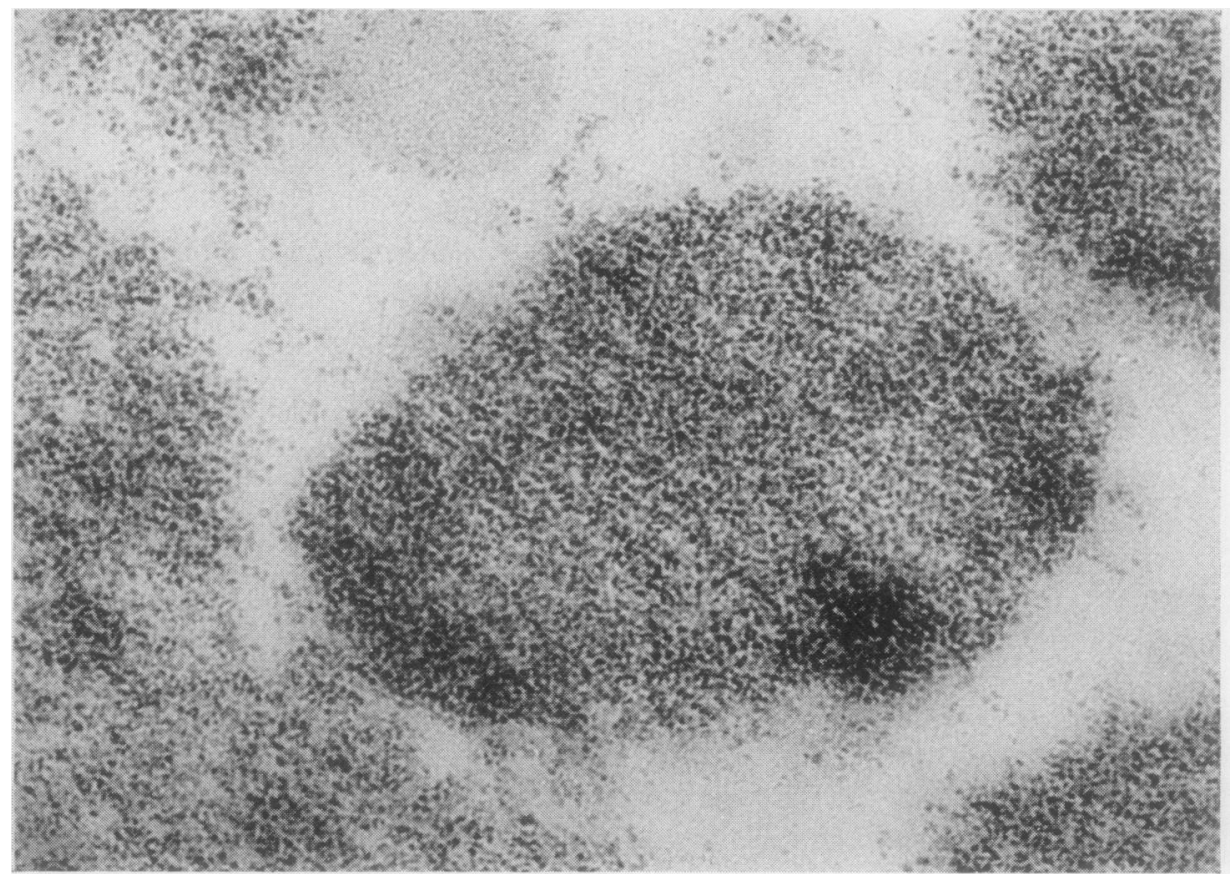

FIG. 7. Porphyria cutanea tarda. A siderosome, lined by a membrane, containing only ferritin molecules. Insert; characteristic configuration of ferritin molecule. $\times 150,000$ and $\times 500,000$

FIG. 8. Porphyria cutanea tarda. A large haemosiderin granule containing ferritin and ferrous micelles in the cytoplasm of a hepatocyte. It is not lined by a membrane. $\times 215,000$

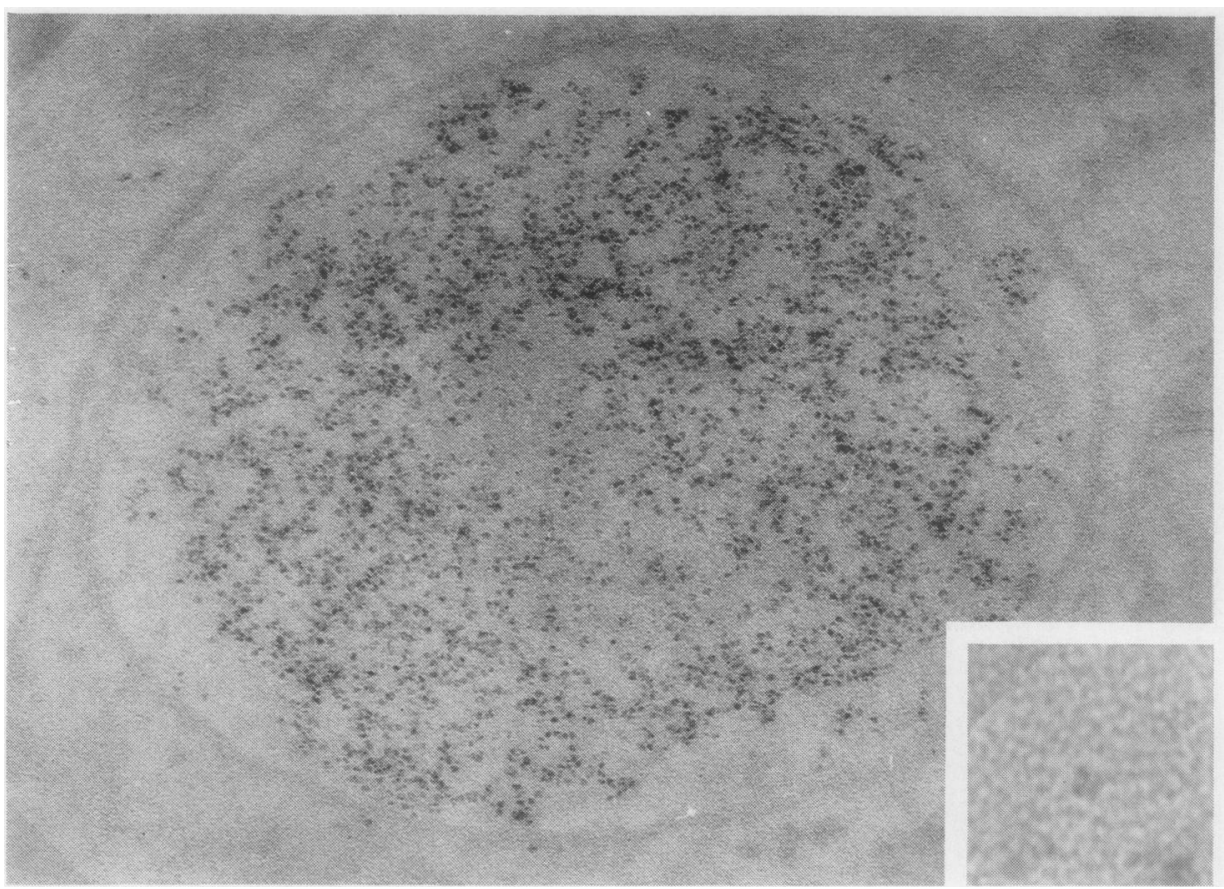

FIG. 7 . 
intermittent porphyria were noted only in one case out of seven; we think that this finding is rare. Equally, the various hepatocytic and sinusoidal alterations previously described are commonly found in different liver diseases (Popper and Schaffner, 1963; David, 1964; Rouiller, 1964). But the constant presence of iron pigment must be emphasized.

Two types of molecule are evident: ferritin and ferrous micelles. Both of them should contain trivalent iron giving a strong Perls' reaction at light microscopy. According to Kent (1965), cytoplasmic iron is stored as ferritin in siderosomes containing various hydrolytic enzymes. These could destroy the apoferritin and release $\mathrm{Fe}^{+++}$which would bind to various substances deriving from the cytolysis of cytoplasmic structures (haemosiderin). This fact agrees with our observation showing that siderosomes, having little iron, are constituted only by ferritin, whereas the biggest haemosiderin granules are formed by two molecules.

The pathogenesis of hepatosiderosis in porphyria cutanea tarda is not clear: excluding the presence of haemochromatosis, hepatosiderosis of the $\mathrm{C}$ and not of the D degree of Uys and Eales (1963) but no cutaneous pigmentation or diabetes mellitus (Bothwell and Finch, 1962), we could postulate that the deposition of iron pigment is connected either with alterations in porphyrinic metabolism or with the liver disease itself.

Hepatosiderosis is frequently observed in various liver disorders, especially in those evolving in cirrhosis: in $50 \%$ of liver biopsy specimens in Milan (Jean and Caprio, 1960), and in $70 \%$ of necropsy specimens (Pechet, French, Levy, and MacDonald, 1965).

Excessive iron intake with alcoholic beverages is the most important cause of the increase in intrahepatic iron in cirrhosis (Berlin and Brante, 1962; Saunders, 1963; Kent, 1965). Chronic alcoholism is common in porphyria cutanea tarda (Waldenström and Haeger, 1960; Kramer, 1963) and a long history of heavy alcohol intake was present in all our patients also. In other alcoholic cirrhoses, the intensity and the frequency of hepatic siderosis is not so remarkable as in porphyria cutanea tarda (Uys and Eales, 1963). Therefore it is possible that alterations in porphyrinic metabolism influence iron metabolism, provoking either a decreased utilization or an increased uptake of iron by the liver. In addition, in porphyria cutanea tarda, there may be increased haemolysis which would raise the ferrous hepatic stores (Prato et al, 1964). Finally it must be underlined that primary lysosomes are not observed in hepatocytes of porphyria cutanea tarda, whereas many siderosomes (secondary lysosomes) are seen (Daems and van Rijssel, 1961; Kent, Minick, Volini, Orfei, and De La Huerga, 1963; Kent, 1965).

This observation raises two hypotheses: (1) Porphyria cutanea tarda could be a so-called lysosome disease (De Duve, 1964; Hers, 1965). In fact in this condition the absence of primary lysosomes and an increased amount of storage materials are the basic characteristic. (2) The decrease in primary lysosomes may be secondary to their fusion with storage granules. If so, the role played by lysosomes in the pathogenesis of porphyria cutanea tarda is not aetiological but secondary. This possibility seems to be more likely because lysosomes are not involved in porphyrinic metabolism.

\section{REFERENCES}

Alessandrini, A., Nazzaro, P., and Topi, G. C. (1964). G. ital. Derm., $105,1$.

Beretta-Anguissola, A. (1961). Minerva med., 52, 2021.

Berlin, S. O., and Brante, G. (1962). Lancet, 2, 729.

Biempica, L., Kosower, N., Roheim, P., London, I. M., and Novikoff, A. B. (1966). Fed. Proc., 25, 362

Bolgert, M., and Canivet, J. (1956). Bull. Soc. franc. Derm. Syph., 63, 373.

Bothwell, T. H., and Finch, C. A. (1962). Iron Metabolism. Little, Brown, Boston. Churchill, London.

Bronfenmajer, S., Schaffner, F., and Popper, H. (1966). Arch. Path., 82, 447.

Campbell, J. A. H. (1963). S.Afr. J. Lab. clin. Med., 9, 197.

Daems, W. T., and van Rijssel, T. G. (1961). J. Ultrastruc. Res., 5, 263.

David, H. (1964). Submicroscopic Ortho- and Patho-Morphology of the Liver. Pergamon Press, Oxford.

De Duve, C. (1964). Fed. Proc. 23, 1045.

Eales, L. (1963). S.Afr. J. Lab. clin. Med., 9, 151.

Dowdle, E. B., and Saunders, S. J. (1963). Ibid., 9, 173.

Hers, H. G. (1965). Gastroenterology, 48, 625.

Jean, G., and Caprio, G. (1960). Arch. ital. Anat. Istol. pat., 34, 259.

Kent, G. (1965). Iron storage disease and the liver. In Progress in liver Disease, edited by H. Popper and F. Schaffner, vol. 2, p. 253. Heinemann, London.

—, Minick, O. T., Yolini, F. I., Orfei, E., and De La Huerga, J. (1963). Lab. Invest., 12, 1102.

Kramer, S. (1963). S.Afr. J. Lab. clin. Med., 9, 283.

Moses, H. L., Suskind, R. G., Tschudy, D. P., and Marver, H. S. (1966). Fed. Proc. A., 25, 361.

Pechet, G. S., French, S. W., Levy, J., and MacDonald, R. A. (1965). Arch. Path., 79, 452.

Perlroth, M. G., Tschudy, D. P., Marver, H. S., Berard, C. W., Zeigel, R. F., Rechcigl, M., and Collins, A. (1966). Amer. J. Med., 41, 149.

Phillips, M. J., and Steiner, J. W. (1966). Lab. Invest., 15, 801.

Popper, H., and Schaffner, F. (1963). Ann. intern. Med., 59, 674.

Prato, V., Chiandussi, L., Massaro, A., Mazza, U., and Zina, G. (1964). Minerva med., 55, 1897.

Richter, G. W. (1957). J. exp. Med., 106, 203.

(1960). Ibid., 112, 551.

Rouiller, C. (1964). Experimental toxic injury of the liver. In The Liver, edited by C. Rouiller, vol. II, p. 335. Academic Press, London.

Saunders, S. J. (1963). S.Afr. J. Lab. clin. Med., 9, 277.

Schmid, R., Schwartz, S., and Watson, C. J. (1954). Arch. intern. Med., 93, 167.

Schnack, H., and Wewalka, F. (1964). T. Gastro-ent., 7b, 342.

Stein, R. J., Richter, W. R., and Brynjolfsson, G. (1966). Exp. molec. Path., 5, 195.

Thaler, H. (1964). Wien. Z. inn. Med., 45, 447.

Tschudy, D. P. (1965). J. Amer. med. Ass., 191, 718.

Tuffanelli, D. L. (1960). U.S. Armed Forces med. J., 11, 1210.

Uys, C. J., and Eales, L. (1963). S.Afr. J. Lab. clin. Med., 9, 190.

Waldenström, J., and Haeger, B. (1960). Ann. intern. Med., 53, 286.

Watson, C. J. (1960). New Engl. J. Med., 263, 1205.

Weissmann, G. (1965). Ibid., 273, 1084 and 1143.

Wills, E. J. (1965). J. Cell. Biol., 24, 511. 